\title{
ESTUDIO ESTADISTICO DE LOS FUNCIONARIOS DE LAS CORPORACIONES LOCALES EN EL PERIODO 1969-1973
}

\author{
$311: 352.084 .3$
}

por

\section{Antonio Rodríguez Socorro}

Jefe de la Sección de Estadística del Instituto de Estudios de Administración Local

SUMARIO: I. EL PERSONAL AL SERVICIO DE LAS CORPORACIONES LOCALES: 1. EN CONJUNTO. 2. POR GRANDES GRUPOS DE PERSONAL. 3. SEgún los Niveles de población de los Municipios. 4. El PERSONAL de los ayuntamientos de Municipios capitales de Provincia. 5. La evoluCIÓN DEL PERSONAL DE PLANTILla SEGÚN CLASES DE FUNCIONARIOS.-II. EL PERSONAL QUE CUBRE PLAZA EN PROPIEDAD: 1. EN CONJUNTO. 2. SU EVOLUCIÓN SEGÚN NIVELES DE POBLACIÓN DE LOS MUNICIPIOS. - III. LAS VACANTES Y EL PERSONAL JUBILADO. - IV. CONCLUSIONES.

\section{EL PERSONAL AL SERVICIO DE LAS CORPORACIONES LOCALES}

Voy a presentar unos esquemas relativos a los funcionarios al servicio de las Corporaciones locales en el quinquenio 1969-1973.

Los datos primarios que sirven de base a la elaboración de ésta han sido tomados del Anuario Estadístico de las Corporaciones Locales de 1974, y que fueron facilitados por las propias Corporaciones al cumplimentar los cuestionarios E.L.S.-3 y E.L.S.-8. 
Los resultados numéricos referentes a los funcionarios han sido elaborados, en parte, bajo mi dirección, por la Sección de Estadística del Instituto de Estudios de Administración Local.

\section{EN CONJUNTO}

La evolución del personal al servicio de las Corporaciones locales — plazas de plantilla, personal sujeto a legislación laboral y personal de servicios concertados- puede deducirse del siguiente cuadro:

CUADRO I.A.1.1

\begin{tabular}{|c|c|c|c|c|c|c|c|}
\hline \multirow[b]{2}{*}{ Corporaciones } & \multirow[b]{2}{*}{1969} & \multirow[b]{2}{*}{1970} & \multirow[b]{2}{*}{1971} & \multirow[b]{2}{*}{1972} & \multirow[b]{2}{*}{1973} & \multicolumn{2}{|c|}{$\begin{array}{l}\text { Incrementos } \\
\text { quinquenio }\end{array}$} \\
\hline & & & & & & $\begin{array}{l}\text { Cifras } \\
\text { absolu. }\end{array}$ & $\%$ \\
\hline En conjunto $\ldots \ldots$ & 187.167 & 189.655 & 193.329 & 197.572 & 204.324 & 17.157 & 9,2 \\
\hline $\begin{array}{l}\text { En las Diputaciones } \\
\text { y Cabildos I. ... }\end{array}$ & 36.348 & 37.305 & 39.354 & 39.670 & 43.616 & 7.268 & 20,0 \\
\hline 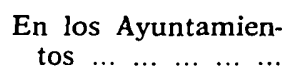 & 150.819 & 152.350 & 153.975 & 157.902 & 160.708 & 9.889 & 6,6 \\
\hline
\end{tabular}

Si consideramos el promedio anual del incremento, se observa que para el conjunto de las Corporaciones equivale a 1,84 por 100, y es más acusado en las Diputaciones y Cabildos insulares, cuyo ritmo de aumento resulta ser del 4 por 100 anual, y en los Ayuntamientos, a nivel inferior, resulta con el 1,3 por 100 de aumento anual.

El incremento registrado en el personal de las Diputaciones y Cabildos insulares ha pasado de $1 / 6$ en el quinquenio anterior a $1 / 5$ en éste.

\section{POR GRANDES GRUPOS DE PERSONAL}

Atendiendo a sus tres componentes básicos: de plantilla, laboral y de servicio concertados, la evolución del personal de las Corporaciones locales en el quinquenio se deduce de las cifras siguientes: 
CUADRO I.B.1.1.1

\begin{tabular}{|c|c|c|c|c|c|}
\hline \multirow{2}{*}{ Grupos de personal } & \multicolumn{5}{|c|}{ En conjunto } \\
\hline & 1969 & 1970 & 1971 & 1972 & 1973 \\
\hline $\begin{array}{l}\text { Plazas de plantilla } \\
\text { Personal sujeto a } \ldots\end{array}$ & $\begin{array}{r}126.947 \\
47.876\end{array}$ & 126.621 & 127.517 & 128.587 & $\begin{array}{l}58.612 \\
14.910\end{array}$ \\
\hline \multirow{2}{*}{ Grupos de personal } & \multicolumn{5}{|c|}{ Diputaciones y Cabildos } \\
\hline & 1969 & 1970 & 1971 & 1972 & 1973 \\
\hline 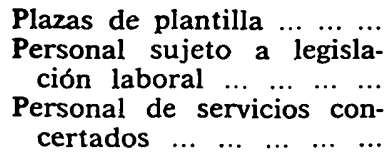 & 18.840 & 18.723 & 19.088 & 19.179 & 19.359 \\
\hline \multirow{2}{*}{ Grupos de personal } & \multicolumn{5}{|c|}{ Ayuntamientos } \\
\hline & 1969 & 1970 & 1971 & 1972 & 1973 \\
\hline 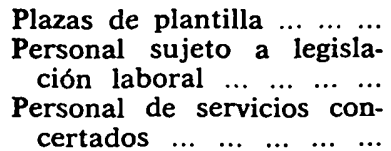 & 108.107 & 107.898 & 108.429 & 109.408 & 111.443 \\
\hline
\end{tabular}

CUADRO I.B.1.1.2

\begin{tabular}{|c|c|c|c|}
\hline \multirow{2}{*}{ Grupos de personal } & \multicolumn{3}{|c|}{ Porcentajes de incremento } \\
\hline & $1969-1973$ & $1969-1973$ & $1969-1973$ \\
\hline $\begin{array}{lllllll}\text { Plazas de plantilla } & \ldots & \ldots & \ldots & \ldots & \ldots & \ldots \\
\text { Personal sujeto a legislación laboral } & \ldots & \ldots & \ldots & \ldots & \ldots \\
\text { Personal de servicios concertados } & \ldots & \ldots & \ldots & \ldots & \ldots\end{array}$ & $\begin{array}{r}3,0 \\
22,4 \\
20,8\end{array}$ & $\begin{array}{r}2,8 \\
45,4 \\
-19,1\end{array}$ & $\begin{array}{r}3,1 \\
11,3 \\
27,8\end{array}$ \\
\hline
\end{tabular}

Del examen de las cifras anteriores se desprende, en primer lugar, un reducido incremento en el personal de plantilla que alcanza al 3 por 100 en el quinquenio y que afecta esta vez por igual a los Ayuntamientos, Diputaciones y Cabildos, con una diferencia de 0,3 por 100 a favor de los Ayuntamientos. En este quinquenio, respecto del anterior, casi se duplica el porcentaje de incremento en los Ayuntamientos, y en las Diputaciones y Cabildos insulares es superior al triple. 
El personal laboral y el de servicios concertados sonı los más afectados por los aumentos: el primero se ha incrementado en casi una quinta parte, a un ritmo anual del 4,5 por 100 para el conjunto de las Corporaciones; en las Diputaciones y Cabildos insulares este personal se ha visto incrementado en casi la mitad, con un aumento anual del 9,1 por 100 , mientras que, con referencia a los Ayuntamientos, el aumento se limita a la décima parte, a un ritmo del 2,26 por 100 anual.

El personal de servicios concertados que no cubre una jornada normal de trabajo registra en el quinquenio, para las Corporaciones en conjunto, un aumento menos acentuado y casi reducido a la mitad del mismo, pues pasa del 41,8 al 20,8 por 100 ; y el incremento en los Ayuntamientos también queda reducido, aproximadamente a la mitad, pues ha pasado del 52,4 al 27,8 por 100 . Respecto a las Diputaciones y Cabildos insulares se observa una disminución superior a la quinta parte.

Como consecuencia de ello se modifica lógicamente la distribución del personal de los tres grupos considerados en relación con las clases de Corporaciones, dando lugar al cuadro I.B.1.2.1, que corresponde a la tabla 1.B.1.2 del A. E. de las C. L., 1974.

CUADRO I.B.1.2.1

\begin{tabular}{|c|c|c|c|c|c|c|}
\hline \multirow[t]{2}{*}{ Grupos de personal } & \multicolumn{2}{|c|}{$\begin{array}{l}\text { Conjunto de } \\
\text { Corporaciones }\end{array}$} & \multicolumn{2}{|c|}{$\begin{array}{l}\text { Diputaciones } \\
\text { provinciales } \\
\text { y Cabildos I. }\end{array}$} & \multicolumn{2}{|c|}{ Ayuntamientos } \\
\hline & 1969 & 1973 & 1969 & 1973 & 1969 & 1973 \\
\hline \multirow{4}{*}{ 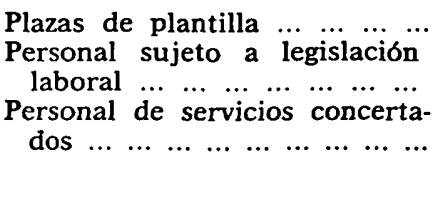 } & 67,8 & 64,0 & 51,8 & 44,4 & 71,7 & 69,3 \\
\hline & 25,6 & 28,7 & 43,1 & 52,2 & 21,4 & 22,3 \\
\hline & 6,6 & 7,3 & 5,1 & 3,4 & 6,9 & 8,4 \\
\hline & 100,0 & 100,0 & 100,0 & 100,0 & 100,0 & $1,00,0$ \\
\hline
\end{tabular}

Hago constar que, aunque todavía se aprecia un claro predominio del personal de plantilla, su peso específico en el conjunto del personal al servicio de las Corporaciones locales tiende a disminuir, tal como se apreciaba en el quinquenio anterior, aunque la diferencia sea menor, en beneficio de los otros dos grupos; así, pasa del 4,3 al 3,8 por 100 , la disminución para el conjunto de las Corporaciones, pero se atenúa la diferencia, como en el quinquenio 
CUADRO I.B.1.2.2

\begin{tabular}{|c|c|c|c|c|c|}
\hline \multirow{2}{*}{ Grupos de personal } & \multicolumn{5}{|c|}{ Conjunto de Corporaciones } \\
\hline & 1969 & 1970 & 1971 & 1972 & 1973 \\
\hline \multirow{4}{*}{ 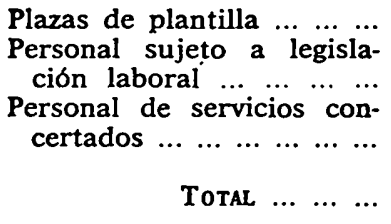 } & 67,8 & 66,8 & 66,0 & 65,1 & 64,0 \\
\hline & 25,6 & 26,2 & 26,5 & 27,2 & 28,7 \\
\hline & 6,6 & 7,0 & 7,5 & 7,7 & 7,3 \\
\hline & 100,0 & 100,0 & 100,0 & 100,0 & 100,0 \\
\hline \multirow{2}{*}{ Grupos de personal } & \multicolumn{5}{|c|}{ Diputaciones provinciales y Cabildos insulares } \\
\hline & 1969 & 1970 & 1971 & 1972 & 1973 \\
\hline \multirow{4}{*}{ 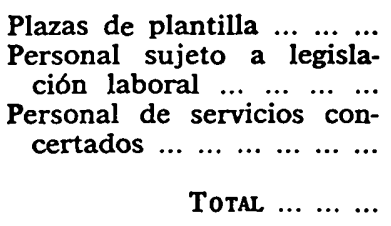 } & 51,8 & 50,2 & 48,5 & 48,3 & 44,4 \\
\hline & 43,1 & 45,6 & 46,9 & 48,2 & 52,2 \\
\hline & 5,1 & 4,2 & 4,6 & 3,5 & 3,4 \\
\hline & 100,0 & 100,0 & 100,0 & 100,0 & 100,0 \\
\hline \multirow{2}{*}{ Grupos de personal } & \multicolumn{5}{|c|}{ Ayuntamientos } \\
\hline & 1969 & 1970 & 1971 & 1972 & 1973 \\
\hline \multirow{3}{*}{ 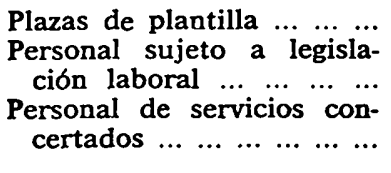 } & 71,7 & 70,8 & 70,4 & 69,3 & 69,4 \\
\hline & 21,4 & 21,5 & 21,3 & 21,9 & 22,8 \\
\hline & 6,9 & 7,7 & 8,3 & 8,8 & 8,3 \\
\hline Total $\ldots \ldots \ldots$ & 100,0 & 100,0 & 100,0 & 100,0 & 100,0 \\
\hline
\end{tabular}

anterior, en relación con las Diputaciones y Cabildos insulares, ya que pasa de 7,1 a 7,4 por 100 . Atendiendo al número de personas que servian a las Corporaciones locales en 1973, se puede señalar que de cada 100 personas 64 eran de plantilla, 29 de personal laboral y 7 de servicios concertados.

Teniendo en cuenta la distribución del personal de Diputaciones y Cabildos insulares en 1973, se observa que existen diferencias con respecto a las Corporaciones, porque de cada 100 personas a su servicio sólo 44 tienen la calificación de personal de plantilla, 52 forman parte del personal sujeto a legislación laboral y 4 son de personal de servicios concertados.

Teniendo en cuenta los Ayuntamientos en el año 1973, de cada 
100 personas a su servicio 69 son de plantilla, 22 son laborales y 9 de servicios concertados.

Se puede seguir diciendo, como los años anteriores, que el incremento de servicios concertados es característico de las Corporaciones y el aumento de personal laboral es propio de las Diputaciones y Cabildos insulares.

\section{Según los niveles de población de los Municipios}

La distribución del personal al servicio de los Ayuntamientos, según el nivel de población de los Municipios, en los momentos extremos del quinquenio, se deduce de estos datos: los resultados expuestos en las tablas I.C.1.1, I.C.1.1.1 y I.C.1.2 del Anuario Estadístico de las Corporaciones Locales, 1974.

Se observa en la tabla I.C.1.1 de la citada publicación que el incremento de personal no se produce con carácter general; de una parte, los valores máximos corresponden a los Ayuntamientos de grandes Municipios, con algo más de la sexta parte. En el primer caso, el incremento es paralelo a la acentuación del fenómeno de concentración de la población en las grandes ciudades y, en el segundo, al aumento de Municipios de este nivel a causa de su pérdida de población. Respecto a las restantes clasificaciones de niveles de población, la situación es cada vez más estacionaria, aunque moderadamente negativa en el grupo de 5.001 a 20.000 habitantes, siendo mayor que en el ciclo anterior, y el cuarto grupo tiene, en el ciclo que se estudia, variación positiva.

La distribución del personal de los Ayuntamientos correspondiente a los Municipios de cada nivel de población es como sigue en los años de referencia:

CUADRO I.C.1.3

Número de habitantes de los Municipios

Porcentajes

\begin{tabular}{ccc}
\hline 1969 & & 1973 \\
$\begin{array}{c}6,1 \\
13,4\end{array}$ & & 6,2 \\
18,8 & & 11,3 \\
21,6 & & 20,5 \\
40,1 & & 44,5 \\
\cline { 1 - 1 } 100,0 & & 100,0 \\
\hline
\end{tabular}


Volvemos a observar cifras casi estables en los porcentajes de 1973 con respecto a los de 1972, con la particularidad siguiente: el aumento de 1969 a 1973 se realiza en los pequeños y grandes Municipios, con una disminución entre el 1 y el 2 por 100 en los niveles de 1.001 a 20.000 y en el de 20.001 a 100.000 , hay estabilidad con ligero aumento. Se puede seguir señalando, como en ciclos anteriores, la acentuación de la concentración de funcionarios en los Ayuntamientos de grandes Municipios, que absorben el 44,5 por 100 del personal al servicio de los mismos. Se puede afirmar que los Municipios mayores de 20.000 habitantes absorben el 65 por 100, casi las dos terceras partes del personal de todos los Ayuntamientos.

La clasificación del mismo, según los grandes grupos de personal que hemos tenido en cuenta en el apartado anterior y los niveles de población de los Municipios, nos proporciona la tabla I.C.1.4 del Anuario Estadístico de las Corporaciones Locales, 1974.

Y las variaciones deducidas de las cifras anteriores dan lugar a la tabla I.C.1.5 del mencionado Anuario. Y nos dicen, que el personal de plantilla únicamente aumenta en los Ayuntamientos de los niveles extremos de población, con porcentaje triplicado respecto del ciclo 1968-1972, y decrece esta vez a ritmo inferior en los Ayuntamientos de los restantes niveles de Municipios.

Respecto del personal laboral, se observa una pequeña diferencia con el ciclo anterior de 1968-1972, ya que en el nivel menor disminuye el personal en dos unidades y los restantes niveles siguen la misma marcha general. Como la intensidad de la variación es distinta en razón de los niveles considerados, se hace notar que el aumento mayor se ha realizado en los Municipios mayores de 5.000 habitantes, que casi es en todos los niveles de un 11 a un 22 por 100 , correspondiendo el valor menor a los mayores de 10.000 habitantes.

En el personal de los servicios concertados se observa en los Ayuntamientos de los grandes Municipios que sigue el ritmo del quinquenio anterior, pasando del 497 al 502 por 100 en él considerado, pero esto es casi normal por partir de una cota muy baja.

Tienen mayor significación los incrementos registrados en los Ayuntamientos de Municipios de 5.001 a 100.000 y de los pequeños, con un incremento medio de un 8 por 100 , y la gran diferencia respecto al ciclo 1968-1972 de ir en disminución el personal de esta clase en los Municipios de 1.001 a 5.000 habitantes. 
Para estudiar las variaciones registradas y ver en qué medida modifican la distribución del personal de los tres grupos, según los niveles de población establecidos, se elaboró la tabla I.C.1.6. del Anuario Estadístico de las Corporaciones Locales, 1974.

En primer lugar, refiriéndonos al personal de plantilla, se advierte un aumento relativo en los niveles de 1.001 a 5.000 y los de más de 100.000 habitantes y una disminución relativa en los niveles restantes. Respecto del personal laboral, si observamos la tabla vemos que no coinciden los aumentos y disminuciones con los habidos en el personal de plantilla. El incremento del personal de servicios concertados es general y afecta a los Ayuntamientos de Municipios de todos los niveles, pero en especial el aumento es mayor en los grandes Municipios.

Si queremos estudiar la distribución interna del personal de los Ayuntamientos, por grupos, en 1973 hay que observar que de cada 100 personas a su servicio en el grupo menor 55 son de plantilla, 11 laborales y 34 de servicios concertados; en el segundo, el personal de plantilla supone de cada 100 personas, 70, 14 para laborales y 16 de servicios concertados; en el tercero, de cada 100 personas, corresponden 65 al personal de plantilla, 25 al laboral y 10 al de servicios concertados; en el cuarto, de cada 100 personas, 63 corresponden al personal de plantilla, 33 al laboral y 4, únicamente, al de servicios concertados, y en el quinto nivel, de cada 100 personas, 76 son de plantilla, 20 de personal laboral y 4 pertenecen al de servicios concertados.

La distribución del personal de cada uno de los grupos anteriores, según niveles de población de los Municipios y en porcentajes, da lugar a la tabla I.C.1.7 del Anuario Estadistico de las Corporaciones Locales, 1974.

Observando dicha tabla vemos que en el ciclo de 1969 a 1973, en el personal de plantilla, el ritmo es análogo al quinquenio 19681972 , con una disminución relativa en los niveles de 1.001 a 100.000 habitantes y un ligero incremento en el primer nivel y un aumento del 48 por 100 en los grandes Municipios. En el personal laboral, únicamente aumentan ligeramente en los Municipios de 2.001 a 100.000 habitantes, y en los restantes, ligeras disminuciones, excepto en los de 1.001 a 5.000 , donde la disminución es del 3,6 por 100.

De otro modo, se puede afirmar que más de las dos terceras partes del personal de plantilla pertenece a Ayuntamientos de $\mathrm{Mu}$ - 
nicipios mayores de 20.000 habitantes, y de análoga manera, el personal laboral, y, sin embargo, en el personal de servicios concertados, en ese nivel, sólo hay un poco más de la tercera parte y tienen mayor porcentaje los Municipios de menor número de habitantes.

4. El personal de los ayuntamientos de Municipios capitales DE Provincia

En el quinquenio 1968-1972 el personal al servicio de los Ayuntamientos de Municipios capitales de Provincia sufrió un aumento del 4,9 por 100 , inferior al de los Ayuntamientos en conjunto y a los de las grandes urbes, y en el quinquenio que estudiamos se pasa en 1969 de 69.093 personas a 72.964 en 1973, con un aumento superior al anterior, en el 5,6 por 100. Como en los Municipios de las capitales los niveles de población no son homogéneos, éstos se consideran como de poca representatividad.

Si deseamos estudiar las variaciones en los grandes grupos de personal utilizaremos los cuadros siguientes:

CUADRO I.D.1.1

\begin{tabular}{|c|c|c|}
\hline Grupos de personal & $\begin{array}{c}\text { Variaciones } \\
\text { absolutas }\end{array}$ & $\begin{array}{l}\text { Porcentajes } \\
\text { de variación }\end{array}$ \\
\hline 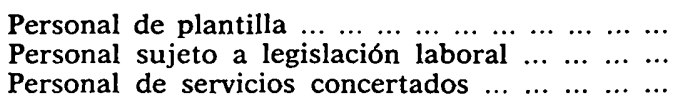 & $\begin{array}{r}2.053 \\
-349 \\
2.167\end{array}$ & $\begin{array}{r}3,9 \\
-2,3 \\
205,2\end{array}$ \\
\hline
\end{tabular}

CUADRO I.D.1.1.1

\begin{tabular}{|c|c|c|c|c|c|}
\hline Grupos de personal & 1969 & 1970 & 1971 & 1972 & 1973 \\
\hline $\begin{array}{l}\text { Personal de plantilla ....... } \\
\text { Personal sujeto a legisla- }\end{array}$ & 53.142 & 53.823 & 53.762 & 54.284 & 55.195 \\
\hline $\begin{array}{l}\text { Personal sujeto a legisia- } \\
\text { ción laboral .............. } \\
\text { Personal de servicios con- }\end{array}$ & 14.895 & 14.969 & 14.268 & 14.560 & 14.546 \\
\hline certados $\ldots \ldots \ldots \ldots \ldots$ & 1.056 & 2.533 & 2.820 & 3.509 & 3.223 \\
\hline
\end{tabular}

Respecto al ciclo 1968-1972 vemos que el personal de plantilla ha aumentado más del doble, pero ha decrecido el personal sujeto a legislación laboral de 1969-1973, que permanecía casi estaciona- 
rio en el ciclo anterior, y el personal de servicios concertados ha decrecido un poco, pero siempre con el aumento exagerado en el quinquenio. En conjunto, el aumento del personal de plantilla de los Ayuntamientos es de un 6 por 100.

Si analizamos la distribución del personal en los tres grupos citados observamos porcentajes análogos a los del ciclo anterior y con los valores siguientes:

CUADRO I.D.1.2

\begin{tabular}{|c|c|c|}
\hline Grupos de personal & 1969 & 1973 \\
\hline 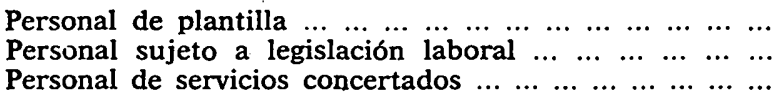 & $\begin{array}{r}76,9 \\
21,6 \\
1,5\end{array}$ & $\begin{array}{r}75,7 \\
19,9 \\
4,4\end{array}$ \\
\hline & 100,0 & 100,0 \\
\hline
\end{tabular}

5. La evolución del personal de Plantilla SEgún Clases DE FUNCIONARIOS

Se estima de gran utilidad el análisis del personal de plantilla, por ser numéricamente el más importante y porque comprende a los funcionarios que dirigen las actividades técnicas y jurídico-administrativas de las Corporaciones.

Su distribución en conjunto y por clases de Corporaciones y de personal en los años extremos del quinquenio 1969 a 1973 y en el quinquenio son las siguientes:

CUADRO I.E.1.1

\begin{tabular}{|c|c|c|c|}
\hline \multirow[b]{2}{*}{ Personal de plantilla } & \multicolumn{3}{|c|}{ Variaciones absolutas } \\
\hline & $\begin{array}{l}\text { Corporaciones } \\
\text { en conjunto } \\
(1969-1973)\end{array}$ & $\begin{array}{l}\text { Diputaciones } \\
\text { y Cabildos } \\
\text { (1969-1973) }\end{array}$ & $\underset{(1969-1973)}{\text { Ayuntamientos }}$ \\
\hline $\begin{array}{lllll}\text { Cuerpos nacionales } & \ldots & \ldots & \ldots & \ldots \\
\text { Personal administrativo } & \ldots & \ldots \\
\text { Personal técnico } \ldots . . . & \ldots & \ldots & \ldots \\
\text { Personal de servicios } & \text { especia- }\end{array}$ & $\begin{array}{r}-347 \\
1.093 \\
253\end{array}$ & $\begin{array}{l}-7 \\
195 \\
247\end{array}$ & $\begin{array}{r}-340 \\
898 \\
6\end{array}$ \\
\hline 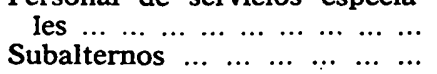 & $\begin{array}{r}4.232 \\
-1.376\end{array}$ & $\begin{array}{r}299 \\
-215\end{array}$ & $\begin{array}{r}3.933 \\
-1.161\end{array}$ \\
\hline
\end{tabular}


CUADRO I.E.1.1 (continuación)

\begin{tabular}{|c|c|c|c|}
\hline \multirow[b]{2}{*}{ Personal de plantilla } & \multicolumn{3}{|c|}{ Variaciones en porcentajes } \\
\hline & $\begin{array}{l}\text { Corporaciones } \\
\text { en conjunto } \\
(1969-1973)\end{array}$ & $\begin{array}{l}\text { Diputaciones } \\
\text { y Cabildos } \\
(1969-1973)\end{array}$ & $\begin{array}{c}\text { Ayuntamientos } \\
(1969-1973)\end{array}$ \\
\hline 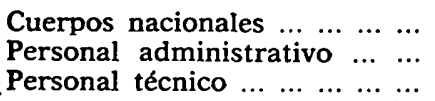 & $\begin{array}{r}-3.8 \\
4,6 \\
2,2\end{array}$ & $\begin{array}{r}-4,0 \\
4,5 \\
5,6\end{array}$ & $\begin{array}{r}-3,8 \\
4,6 \\
0,1\end{array}$ \\
\hline 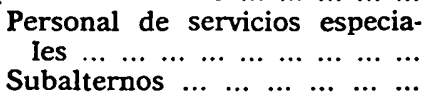 & $\begin{array}{r}6,4 \\
-8,5\end{array}$ & $\begin{array}{r}4,2 \\
-7,8\end{array}$ & $\begin{array}{r}6,7 \\
-8,6\end{array}$ \\
\hline
\end{tabular}

CUADRO I.E.1.1.1

\begin{tabular}{|c|c|c|c|c|c|}
\hline \multirow{2}{*}{ Personal de plantilla } & \multicolumn{5}{|c|}{ Corporaciones en conjunto } \\
\hline & 1969 & 1970 & 1971 & 1972 & 1973 \\
\hline 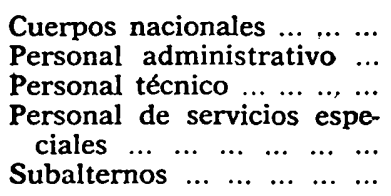 & $\begin{array}{r}9.185 \\
23.985 \\
11.266 \\
\\
66.269 \\
16.242\end{array}$ & $\begin{array}{r}8.952 \\
23.966 \\
11.133 \\
\\
67.353 \\
15.217\end{array}$ & $\begin{array}{r}8.837 \\
24.296 \\
11.114 \\
\\
67.879 \\
15.391\end{array}$ & $\begin{array}{r}8.826 \\
24.551 \\
11.203 \\
69.282 \\
14.725\end{array}$ & $\begin{array}{r}8.838 \\
25.078 \\
11.519 \\
70.501 \\
14.866\end{array}$ \\
\hline \multirow{2}{*}{ Personal de plantilla } & \multicolumn{5}{|c|}{ Diputaciones y Cabildos } \\
\hline & 1969 & 1970 & 1971 & 1972 & 1973 \\
\hline 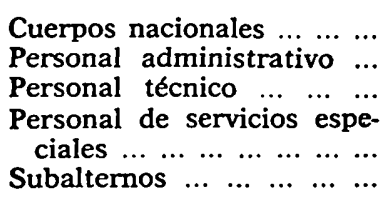 & $\begin{array}{r}176 \\
4.370 \\
4.388\end{array}$ & $\begin{array}{r}173 \\
4.374 \\
4.465\end{array}$ & $\begin{array}{r}168 \\
4.462 \\
4.462\end{array}$ & $\begin{array}{r}173 \\
4.480 \\
4.529\end{array}$ & $\begin{array}{r}169 \\
4.565 \\
4.635\end{array}$ \\
\hline \multirow{2}{*}{ Personal de plantilla } & \multicolumn{5}{|c|}{ Ayuntamientos } \\
\hline & 1969 & 1970 & 1971 & 1972 & 1973 \\
\hline $\begin{array}{l}\text { Cuerpos nacionales } \ldots \\
\text { Personal administrativo }\end{array}$ & $\begin{array}{r}9.009 \\
19.615 \\
6.878\end{array}$ & $\begin{array}{r}8.779 \\
19.592 \\
6.668\end{array}$ & $\begin{array}{r}8.669 \\
19.384 \\
6.652\end{array}$ & $\begin{array}{r}8.653 \\
20.071 \\
6.674\end{array}$ & $\begin{array}{r}8.669 \\
20.513 \\
6.884\end{array}$ \\
\hline 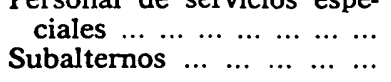 & $\begin{array}{l}59.125 \\
13.480\end{array}$ & $\begin{array}{l}59.974 \\
12.885\end{array}$ & $\begin{array}{l}60.575 \\
12.699\end{array}$ & $\begin{array}{l}61.704 \\
12.306\end{array}$ & $\begin{array}{l}63.058 \\
12.319\end{array}$ \\
\hline
\end{tabular}


Señalado anteriormente el escaso incremento registrado en el quinquenio por el personal de plantilla de las Corporaciones locales, resultaría interesante la observación de las distintas clases de funcionarios.

Se registra, en primer lugar, una disminución que no llega al 4 por 100 en el personal de Cuerpos nacionales, que se acentúa en el subalterno al acercarse al 9 por 100; en segundo lugar, un aumento de casi un 5 por 100 en el personal administrativo, y un suave aumento en el personal técnico de más de un 2 por 100 y un incremento pronunciado de casi un 7 por 100 en el personal de servicios especiales.

Si consideramos, paralelamente, el personal de los Ayuntamientos observamos grandes analogías con el personal de las Corporaciones en conjunto, excepto en el personal técnico, que aquí se ha estabilizado en el quinquenio considerado. En las Diputaciones y Ayuntamientos es análogo el aumento del personal administrativo, y de un aumento en menos del 3 por 100 del personal de servicios especiales de las Diputaciones respecto a los Ayuntamientos; la disminución del personal de Cuerpos nacionales es análoga en las dos Corporaciones, y el personal subalterno disminuye con un poco más de intensidad en los Ayuntamientos.

Vamos a pasar al análisis de las cifras absolutas, por clases de funcionarios, que se insertan en los resúmenes nacionales de la monografía $(2,3,4)(1)$, para establecer los Cuerpos, clases de funcionarios, categorías y especialidades más afectadas por las variaciones numéricas en el quinquenio, aunque en el conjunto desde 1969 a 1973 la tendencia es a un aumento progresivo de menos de 1.000 por año.

En los Cuerpos nacionales se aprecia lo siguiente: su conjunto ha permanecido estable con respecto a 1972, pero ha tenido una disminución de efectivos en los Cuerpos de Depositarios y Directores de Bandas de Música; en el conjunto de Corporaciones y en los Ayuntamientos hay una disminución que tiende a la estabilidad, con la particularidad de tener casi los mismos valores en 1971 y 1973, y en las Diputaciones provinciales y Cabildos insulares ha disminuido progresivamente, con gran aproximación, con seis personas por año. Para el Cuerpo de Interventores se observa que en el conjunto de las Corporaciones locales se estabiliza, e igual en

(1) Anuario Estadístico de las Corporaciones Locales, Madrid, Instituto de Estudios de Administración Local, 1974. 
las Diputaciones y Cabildos, pero en los Ayuntamientos únicamente se presenta la estabilización en los dos últimos años con respecto a los dos primeros del quinquenio, con valor no coincidente en 1971.

En el personal administrativo, en conjunto, se observa un incremento anual aproximado de 200 personas, que afecta a la escala auxiliar en el mismo tono; en la escala técnico-administrativa es casi estable en Corporaciones y Ayuntamientos, y en Diputaciones y Cabildos hay un pequeño aumento progresivo; disminuyen los oficiales mayores en las Corporaciones en conjunto y en los Ayuntamientos, permaneciendo estable en las Diputaciones y Cabildos; aumento pequeño de los viceinterventores; aumentos de un 5 por 100 anual en los jefes de sección y un poco mayor de los subjefes, aunque en éstos sea estable el número en los Ayuntamientos, y los jefes y subjefes de negociado presentan un aumento poco pronunciado en Corporaciones en conjunto y Ayuntamientos y estabilidad en las Diputaciones y Cabildos.

En el personal técnico de las Corporaciones, en conjunto, se aprecia una disminución de unos 50 por año, reflejándose en la escala superior, mientras permanece estacionaria la auxiliar. En el conjunto del personal técnico de las Diputaciones y Cabildos se observa un aumento de 50 técnicos por año en los superiores y una estabilidad en los Ayuntamientos. Por especialidades se observa en las Diputaciones y Cabildos un aumento de 15 por año en técnicos superiores; poco aumento en letrados; médicos con un aumento de 20 por año, y casi estable en ingenieros, veterinarios y archiveros, y disminuye poco el número de odontólogos y farmacéuticos, y los técnicos auxiliares y practicantes aumentan alrededor de 30 por año, y la mitad de los peritos, ayudantes y aparejadores, mientras que el número de maestros de educación primaria y auxiliares de archivos y bibliotecas permanece casi estable, pero aparece una disminución de casi el 50 por 100 respecto de los otros años del quinquenio en las matronas. En los Ayuntamientos, en conjunto, se observa una estabilidad, y en las especialidades de técnicos superiores, letrados, aunque éstos con un aumento que consideramos excesivo en 1969, odontólogos, archiveros y veterinarios en los dos primeros años del ciclo y en 1973, y teniendo poca disminución los restantes, y respecto de los técnicos auxiliares disminuyen, tendiendo a la estabilidad en el ciclo, e igual son estables las matronas y auxiliares de archivos y bibliotecas, y aumentan pe- 
ritos, ayudantes y aparejadores y otro personal docente, y disminuyen los maestros de educación primaria casi 40 por año.

En el personal de servicios especiales al servicio de las Corporaciones locales, en conjunto hay un aumento progresivo anual de más de 800 personas que afecta a guardias y bomberos, y con ligero aumento conductores en las Diputaciones provinciales y Cabildos insulares y guardias y bomberos en los Ayuntamientos.

Respecto del Cuerpo de subalternos está generalizada la reducción, tanto en el conjunto de las Corporaciones locales como en las Diputaciones y Cabildos y Ayuntamientos.

Para estudiar las notables diferencias de la distribución por clases de funcionarios de las Diputaciones y Cabildos respecto de los Ayuntamientos se realiza el siguiente cuadro con cifras correspondientes a 1973:

CUADRÒ I.E.1.2

\begin{tabular}{|c|c|c|}
\hline Personal de plantilla & $\begin{array}{c}\text { Diputaciones } \\
\text { y Cabildos }\end{array}$ & Ayuntamientos \\
\hline 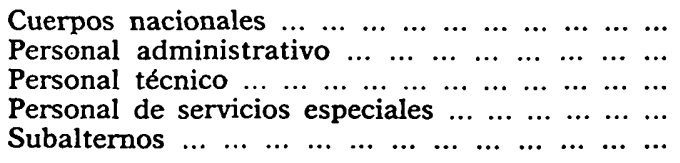 & $\begin{array}{r}0,9 \\
23,6 \\
23,9 \\
38.4 \\
13,2\end{array}$ & $\begin{array}{r}7,8 \\
18,4 \\
6,2 \\
56,6 \\
11,0\end{array}$ \\
\hline 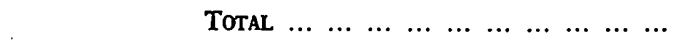 & 100,0 & 100,0 \\
\hline
\end{tabular}

En las Diputaciones y Cabildos y en los Ayuntamientos, en el quinquenio 1969-1973, la variación es análoga en todos los sentidos y casi con el mismo tanto por ciento que en el quinquenio anterior, $\mathrm{y}$, como en aquél, en las Diputaciones y Cabildos el peso relativo del personal de Cuerpos nacionales es muy reducido, no llegando al 1 por 100; el personal administrativo es muy superior en las Diputaciones y Cabildos al de los Ayuntamientos, y el personal de servicios especiales es inferior en Diputaciones y Cabildos al de los Ayuntamientos, que representan más de la mitad de todo el personal de plantilla. Respecto de los subalternos hay un ligero equilibrio del número en Diputaciones y Cabildos y Ayuntamientos.

La distribución, por Cuerpos y clases de funcionarios, de la variación del personal de los Ayuntamientos, según el nivel de población de los Municipios respectivos, es la siguiente: 
CUADRO I.E.1.3

\begin{tabular}{|c|c|c|c|c|c|c|}
\hline \multirow{2}{*}{\multicolumn{2}{|c|}{$\begin{array}{c}\text { Población } \\
\text { de los Municipios }\end{array}$}} & \multicolumn{5}{|c|}{ Variaciones absolutas } \\
\hline & & $\begin{array}{l}\text { Cuerpos } \\
\text { nacional. } \\
(1969-1973)\end{array}$ & $\begin{array}{c}\text { Adminis- } \\
\text { trativos } \\
(1969-1973)\end{array}$ & $\begin{array}{l}\text { Técnicos } \\
(1969-1973)\end{array}$ & $\begin{array}{l}\text { Servicios } \\
\text { especiales } \\
\text { (1969-1973) }\end{array}$ & $\begin{array}{c}\text { Subal- } \\
\text { ternos } \\
(1969-1973)\end{array}$ \\
\hline \multirow{3}{*}{\multicolumn{2}{|c|}{\begin{tabular}{llrlll} 
Hasta 1.000 & \multicolumn{3}{c}{ habitantes } & $\ldots$ \\
De 1.001 a & 5.000 & $\ldots$ & $\ldots$ & $\ldots$ \\
De 5.001 a & 20.000 & $\ldots$ & $\ldots$ & $\ldots$ \\
De 20.001 & a & 100.000 & $\ldots$ & $\ldots$ & $\ldots$ \\
Más de 100.000 & $\ldots$ & $\ldots$ & $\ldots$ & $\ldots$
\end{tabular}}} & $\begin{array}{r}253 \\
-492 \\
-216 \\
73 \\
42\end{array}$ & $\begin{array}{r}172 \\
-107 \\
-382 \\
117 \\
1.098\end{array}$ & $\begin{array}{r}-29 \\
-106 \\
-\quad 81 \\
-\quad 79 \\
301\end{array}$ & $\begin{array}{r}31 \\
-\quad 64 \\
-440 \\
-837 \\
5.243\end{array}$ & $\begin{array}{r}99 \\
-249 \\
-478 \\
-800 \\
267\end{array}$ \\
\hline & & \multicolumn{5}{|c|}{ Variaciones en porcentajes } \\
\hline & & $\begin{array}{c}\text { Cuerpos } \\
\text { nacional. } \\
\text { (1969-1973) }\end{array}$ & $\begin{array}{c}\text { Adminis- } \\
\text { trativos } \\
(1969-1973)\end{array}$ & $\begin{array}{l}\text { Técnicos } \\
\text { (1969-1973) }\end{array}$ & $\begin{array}{l}\text { Servicios } \\
\text { especiales } \\
(1969-1973)\end{array}$ & $\begin{array}{c}\text { Subal- } \\
\text { ternos } \\
(1969-1973)\end{array}$ \\
\hline \begin{tabular}{lrrrr} 
Hasta 1.000 & \multicolumn{2}{rl}{ habitantes } \\
De & 1.001 a & 5.000 & $\ldots$ & $\ldots$ \\
De & 5.001 a & 20.000 & $\ldots$ & $\ldots$ \\
De 20.001 & a & 100.000 & $\ldots$ & $\ldots$ \\
Más de & 100.000 & $\ldots$ & $\ldots$ & $\ldots$
\end{tabular} & $\begin{array}{l}\cdots \\
\cdots \\
\cdots \\
\cdots \\
\cdots\end{array}$ & $\begin{array}{r}7,5 \\
-15.7 \\
-11,3 \\
14,9 \\
44,2\end{array}$ & $\begin{array}{r}36,8 \\
-\quad 2,7 \\
-\quad 7,2 \\
2,9 \\
18,5\end{array}$ & $\begin{array}{r}-11,6 \\
-23,8 \\
-20,9 \\
-10,7 \\
6.0\end{array}$ & $\begin{array}{r}15,9 \\
-\quad 2,0 \\
-4,6 \\
-\quad 6,1 \\
16,2\end{array}$ & $\begin{array}{r}14,0 \\
-8,2 \\
-10,9 \\
-24,0 \\
7,5\end{array}$ \\
\hline
\end{tabular}

Se observa en el personal de los Cuerpos nacionales en los $\mathrm{Mu}$ nicipios de más de 20.000 habitantes y en los menores de 1.001 que aumentan, teniendo un fuerte aumento en los mayores, de una sexta parte en los menores y un tercio en el restante, y una disminución de un 13 por 100 , en promedio, de los mayores de 1.000 a 20.000 habitantes.

En el personal administrativo vemos que existe un notable crecimiento cuando pertenece a los Ayuntamientos de los Municipios más pequeños, un 37 por 100 , y en los de los grandes Municipios la mitad, mientras disminuye en los de los Municipios mayores de 1.000 a 20.000 habitantes, y con ligero aumento los mayores de 20.000 a 100.000 habitantes.

En el personal técnico observamos en los Ayuntamientos de los Municipios de hasta 100.000 habitantes una disminución, siendo la más acusada en la de mayores de 1.000 a 2.000 habitantes, que representa menos de la cuarta parte, y la menos acusada, la décima parte, y tan sólo los Ayuntamientos de los grandes Municipios han aumentado un 5 por 100 su personal técnico.

El personal de servicios especiales y los subalternos aumentan en los Ayuntamientos de los pequeños y grandes Municipios y dis- 
minuyen en los restantes, pero en la proporción de 1 a 4, en ese orden.

Si examinamos las tablas 5.1.a, b, c, d y e del Anuario, que dan las variaciones en cifras absolutas de las distintas clases de personal al servicio de los Ayuntamientos para los distintos niveles de población, se advierte para las distintas clases:

a) En el personal de Cuerpos nacionales, en conjunto, según los niveles ordenados de menor a mayor población, se observa un crecimiento suave, una baja profunda, una baja pronunciada, una subida suave $\mathrm{y}$, por último, para el de mayor nivel un aumento progresivo aproximado de cinco por año; respecto de los secretarios, en los menores hay aumento suave, baja en los de 1.001 a 20.000 y vuelve a aumentar suavemente en los mayores; respecto de los interventores existe una gran estabilidad en los menores y mayores y en los intermedios, excepto en el año 1970, que tiene gran aumento; respecto de los depositarios baja en los tres niveles pequeños y sube en los dos restantes, y los directores de bandas de música se estabilizan en los niveles extremos y bajan poco en los tres restantes.

b) En el personal administrativo únicamente crece en conjunto el personal de menor nivel, y los demás o decrecen o permanecen estables, como en el nivel de 20.001 a 100.000 habitantes, correspondiendo a la escala técnico-administrativa y oficiales aumentos moderados, permaneciendo casi estable en los niveles altos los oficiales mayores.

c) En el personal técnico, en conjunto, únicamente permanece estable el nivel superior a 100.000 habitantes, y los demás sufren bajas, siendo las más profundas las que sufren las del nivel de 20.001 a 100.000 habitantes, correspondiendo a los técnicos superiores una moderada disminución en todos los niveles; arquitectos e ingenieros,' casi estable; médicos, estable, excepto en el nivel de 20.001 a 100.000 habitantes, que se reduce a un tercio; veterinarios, estable en todos los niveles, e igual los archiveros, sobre todo en los de nivel máximo; maestros de primera enseñanza han sufrido un decrecimiento enorme en todos los niveles, llegando en el menor nivel a su desaparición y en los demás a reducción a la mitad; practicantes, estable en los niveles alto y bajo, pero menor en el de 5.001 a 20.000 habitantes; y las matronas tienden a desaparecer en varios niveles, y en el nivel más alto disminuyen levemente. 
d) En el personal de servicios especiales, en conjunto, es mayor en 3.582 personas, que corresponden en su mayoría a guardias, con 2.248; celadores, que baja excesivamente en 1971, y conductores, que baja mucho en los dos últimos años; en el nivel más alto y en los demás niveles, en general, es estable.

e) El personal subalterno, en conjunto, aumenta en el nivel superior a 100.000 habitantes y disminuye en los demás, siendo la disminución más profunda la que corresponde al nivel de 20.001 a 100.000 habitantes.

Examinando la distribución del personal de los Ayuntamientos por clases y niveles de población de sus Municipios en 1973, que se expone en la tabla I.E.1.4. del Anuario Estadistico de las Corporaciones Locales, 1974, observamos que el peso relativo del personal de Cuerpos nacionales de los Ayuntamientos decrece a medida que avanzamos en el nivel poblacional de los respectivos Municipios, tendencia lógica si se tiene en cuenta el número de Corporaciones que rigen los Municipios de cada nivel. En sentido inverso se distribuye el personal de servicios especiales, como consecuencia del paralelismo con la amplitud y complejidad de los servicios a cargo de los Ayuntamientos. El personal administrativo se presenta con irregularidad, teniendo el máximo valor en los Ayuntamientos de Municipios de 1.001 a 5.000 habitantes. El personal técnico ofrece la máxima en los grandes Municipios, cosa lógica. El peso relativo de los subalternos disminuye, de menor a mayor población de Ios Municipios, con la excepción de los Ayuntamientos de Municipios de 1.001 a 5.000 habitantes, que tiene un valor triple del menor.

En los Ayuntamientos de Municipios más pequeños el personal de Cuerpos nacionales supone casi las dos terceras partes de todo el personal; entre administrativos y subalternos absorben la cuarta parte, y el personal de servicios especiales y técnicos, el resto. En los Ayuntamientos de Municipios de 5.001 a 100.000 habitantes se observa un acusado aumento del personal de servicios especiales, análogo al de 1972, con disminución de las restantes clases de funcionarios en comparación con la distribución del personal de los Ayuntamientos de Municipios del nivel anterior, que tienen la mitad del porcentaje. En los grandes Municipios el personal técnico ocupa más de la tercera parte, y la quinta parte de éste, el personal administrativo, y el resto, las otras clases de funcionarios. 
En los Ayuntamientos de Municipios de capitales de Provincia -cuadro 6 (2) - el personal de los Cuerpos nacionales se mantiene en una situación estacionaria, al igual que todos los de su grupo. El personal administrativo, en conjunto, aumenta lentamente, llegando a ser de 43 por año, siendo estables los oficiales mayores, subjefes de sección, subjefes de negociado y oficiales, y los otros siguen la tendencia del conjunto. El personal técnico superior aumenta un poco en el ciclo, notándose, sobre todo, en arquitectos, ingenieros, médicos, y los restantes, en una situación estacionaria; en cuanto al personal técnico auxiliar, los practicantes aumentan, disminuyen considerablemente los maestros de enseñanza primaria, y los restantes, estables. El personal de servicios especiales aumenta en unos 509 por año, correspondiendo el mayor porcentaje a guardias y bomberos, con merma de los demás. Los subalternos disminuyen, aproximadamente, 158 por año.

El peso relativo del personal de los Ayuntamientos de los Municipios capitales de Provincia, por clases de funcionarios, es, en líneas generales, muy parecido al de los Ayuntamientos de los grandes Municipios.

\section{EL PERSONAL QUE CUBRE PLAZA EN PROPIEDAD}

\section{EN CONJUNTO}

El personal que cubre plaza en propiedad y su relación al personal de plantilla, por clases de Corporaciones, fueron las siguientes, en los años 1969 y 1973, en valores absolutos y porcentajes y valores absolutos en el quinquenio: tabla I.2.A.1 del Anuario Estadistico de las Corporaciones Locales, 1974, y cuadro I.2.A.1.1.

CUADRO I.2.A.1.1

\begin{tabular}{|c|c|c|c|c|c|}
\hline \multirow{2}{*}{ Corporaciones } & \multicolumn{5}{|c|}{ Plazas en propiedad } \\
\hline & 1969 & 1970 & 1971 & 1972 & 1973 \\
\hline $\begin{array}{lllllll}\text { En conjunto } & \ldots & \ldots & \ldots & \ldots & \ldots \\
\text { Diputaciones } & \text { y } & \text { Cabildos } & \ldots \\
\text { Ayuntamientos } & \ldots & \ldots & \ldots & \ldots\end{array}$ & $\begin{array}{r}105.845 \\
15.947 \\
89.898\end{array}$ & $\begin{array}{r}106.533 \\
15.872 \\
90.661\end{array}$ & $\begin{array}{r}106.090 \\
15.901 \\
90.189\end{array}$ & $\begin{array}{r}104.709 \\
15.832 \\
88.877\end{array}$ & $\begin{array}{r}105.095 \\
15.874 \\
89.221\end{array}$ \\
\hline
\end{tabular}

(2) Ver Anuario Estadístico de las Corporaciones Locales, Madrid, 1974. 
CUADRO I.2.A.1.1 (continuación)

\begin{tabular}{|c|c|c|c|c|c|}
\hline \multirow{2}{*}{ Corporaciones } & \multicolumn{5}{|c|}{ Personal de plantilla } \\
\hline & 1969 & 1970 & 1971 & 1972 & 1973 \\
\hline $\begin{array}{llllll}\text { En conjunto } & \ldots & \ldots & \ldots & \ldots & \ldots \\
\text { Diputaciones } & \text { y } & \text { Cabildos } & \ldots \\
\text { Ayuntamientos } & \ldots & \ldots & \ldots & \ldots\end{array}$ & $\begin{array}{r}126.947 \\
18.840 \\
108.107\end{array}$ & $\begin{array}{r}126.621 \\
18.723 \\
107.898\end{array}$ & $\begin{array}{r}127.517 \\
19.088 \\
108.429\end{array}$ & $\begin{array}{r}128.587 \\
19.179 \\
109.408\end{array}$ & $\begin{array}{r}130.802 \\
19.359 \\
111.443\end{array}$ \\
\hline
\end{tabular}

Respecto del personal en propiedad se nota un descenso suave en el conjunto y en las Corporaciones, todo lo contrario del personal de plantilla que tiene aumentos, siendo el de mayor peso relativo el de los Ayuntamientos. La relación de plazas en propiedad respecto de las de plantilla es casi homogénea, sobresaliendo únicamente el valor correspondiente a Cabildos y Diputaciones. Como el porcentaje del total es para el personal de plantilla del 55 por 100 y para el personal en propiedad del 45 por 100, la relación de uno y otro es, aproximadamente, de $5 / 4$.

Por Cuerpos y clases de funcionarios, según las clases de Corporaciones, las cifras absolutas y relativas correspondientes están expuestas en la tabla I.2.A.2 del Anuario Estadistico de las Corporaciones Locales, 1974.

Las variaciones operadas en el quinquenio 1969-1973 en el personal que cubre plaza en propiedad son muy significativas, y si exceptuamos a los funcionarios de servicios especiales, con un incremento moderado contrario al de los otros, con evidente disminución, sobre todo los subalternos. Como consecuencia de ello se reduce el peso relativo del personal en propiedad en relación con el de plantilla. En las Diputaciones y Cabildos esta disminución afecta al personal técnico y subalterno, y en los Ayuntamientos únicamente aumenta el personal de servicios especiales. Teniendo en cuenta el porcentaje del personal que cubre plaza en propiedad en relación con el personal de plantilla, se observa una notable disminución en el personal técnico, tanto en Diputaciones y Cabildos como en Ayuntamientos; en los demás la disminución es moderada.

2. Su eVolución SeGún Niveles de población de los Municipios

Esta evolución puede deducirse de las cifras de la tabla I.2.B.1 del Anuario Estadístico de las Corporaciones Locales, 1974, y del cuadro I.2.B.1.1. 
CUADRO I.2.B.1.1

\begin{tabular}{|c|c|c|c|c|c|}
\hline \multirow{2}{*}{$\begin{array}{l}\text { Número de habitantes } \\
\text { de los Municipios }\end{array}$} & \multicolumn{5}{|c|}{ Plazas en propiedad } \\
\hline & 1969 & 1970 & 1971 & 1972 & 1973 \\
\hline 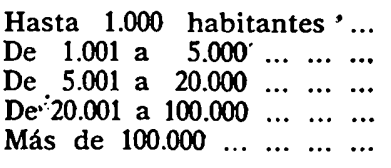 & $\begin{array}{r}2.979 \\
11.418 \\
16.982 \\
19.458 \\
39.061\end{array}$ & $\begin{array}{r}2.985 \\
11.313 \\
16.948 \\
19.422 \\
39.993\end{array}$ & $\begin{array}{r}3.514 \\
10.768 \\
14.636 \\
16.962 \\
44.309\end{array}$ & $\begin{array}{c}3.335 \\
10.566 \\
14.656 \\
16.966 \\
43.354\end{array}$ & $\begin{array}{r}3.344 \\
10.355 \\
14.763 \\
17.097 \\
43.662\end{array}$ \\
\hline \multirow{2}{*}{$\begin{array}{l}\text { Número de habitantes } \\
\text { de los Municipios }\end{array}$} & \multicolumn{5}{|c|}{ Personal de plantilla } \\
\hline & 1969 & 1970 & 1971 & 1972 & 1973 \\
\hline 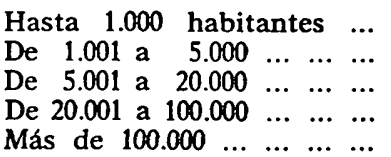 & $\begin{array}{r}4.993 \\
13.712 \\
19.974 \\
22.291 \\
47.137\end{array}$ & $\begin{array}{r}4.815 \\
13.297 \\
19.862 \\
22.139 \\
47.785\end{array}$ & $\begin{array}{r}5.536 \\
12.661 \\
17.736 \\
19.712 \\
52.784\end{array}$ & $\begin{array}{r}5.286 \\
12.810 \\
17.964 \\
20.107 \\
53.241\end{array}$ & $\begin{array}{r}5.519 \\
12.694 \\
18.377 \\
20.765 \\
54.088\end{array}$ \\
\hline
\end{tabular}

La evolución del personal en propiedad y el de plantilla es de tipo análogo, tanto en los aumentos como en las disminuciones correspondientes a cada nivel de población.

Como complemento de la tabla I.2.B.1 se presenta en el Anuario Estadistico de las Corporaciones Locales, 1974, la tabla I.2.B.2, referida a la evolución del personal que cubre plaza en propiedad en relación con el de plantilla por niveles de población de los $\mathrm{Mu}$ nicipios y clases de funcionarios.

Del estudio de dichas tablas se deduce una disminución del personal de los Cuerpos nacionales que cubre plaza en propiedad en los Ayuntamientos de Municipios de 1.001 a 20.000 habitantes, que contrasta con el incremento que se registra en los restantes Ayuntamientos, entre ellos los de mayor nivel poblacional. Análogamente siguen la misma tendencia y en los mismos niveles el personal administrativo; técnicos, con una ligera variación en el nivel de 20.001 a 100.000 habitantes, que pasa a menos; el personal de servicios especiales con igual tendencia que los anteriores, y los subalternos, con detrimento en los niveles intermedios y aumentos en los niveles extremos de los Municipios.

El peso relativo del personal propietario en relación con el de plantilla en los Cuerpos nacionales decrece en los tres primeros niveles, se conserva estacionario en el siguiente y aumenta en el 
nivel de más de 10.000 habitantes: sin embargo, en los técnicos y servicios especiales decrecen en todos los niveles, y los administrativos y subalternos siguen paralelamente su tendencia menos en el último nivel, en que los administrativos decrecen y los subalternos aumentan.

La evolución del personal propietario y en relación con el de plantilla en los Ayuntamientos de Municipios capitales de Provincia se deduce de las tabla I.2.B.3 del Anuario Estadístico de Corporaciones Locales, 1974, y del cuadro I.2.B.3.1.

CUADRO I.2.B.3.1

\begin{tabular}{|c|c|c|c|c|c|}
\hline \multirow{2}{*}{ Clases de funcionarios } & \multicolumn{5}{|c|}{ Plazas de plantilla } \\
\hline & 1969 & 1970 & 1971 & 1972 & 1973 \\
\hline 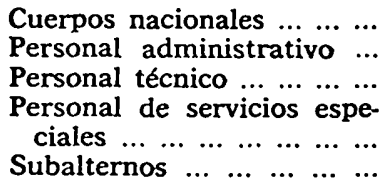 & $\begin{array}{r}180 \\
6.693 \\
5.251 \\
36.238 \\
4.780\end{array}$ & $\begin{array}{r}180 \\
6.768 \\
5.123\end{array}$ & $\begin{array}{r}178 \\
6.743 \\
5.259\end{array}$ & $\begin{array}{r}179 \\
6.693 \\
5.200 \\
\\
37.905 \\
4.307\end{array}$ & $\begin{array}{r}179 \\
6.908 \\
5.336 \\
38.784 \\
3.988\end{array}$ \\
\hline \multirow{2}{*}{ Clases de funcionarios } & \multicolumn{5}{|c|}{ Plazas en propiedad } \\
\hline & 1969 & 1970 & 1971 & 1972 & 1973 \\
\hline 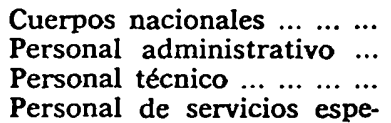 & $\begin{array}{r}161 \\
5.646 \\
4.255\end{array}$ & $\begin{array}{r}157 \\
5.686 \\
4.200\end{array}$ & $\begin{array}{r}151 \\
5.632 \\
4.331\end{array}$ & $\begin{array}{r}152 \\
5.421 \\
4.179\end{array}$ & $\begin{array}{r}157 \\
5.482 \\
4.111\end{array}$ \\
\hline $\begin{array}{cccccccc}\text { ciales } & \ldots & \ldots & \ldots & \ldots & \ldots & \ldots & \ldots \\
\text { Subalternos } & \ldots & \ldots & \ldots & \ldots & \ldots\end{array}$ & $\begin{array}{r}30.973 \\
3.815\end{array}$ & $\begin{array}{r}32.270 \\
3.595\end{array}$ & $\begin{array}{r}32.110 \\
3.671\end{array}$ & $\begin{array}{r}31.589 \\
3.534\end{array}$ & $\begin{array}{r}32.051 \\
3.260\end{array}$ \\
\hline
\end{tabular}

Se observa que en las plazas de plantilla disminuye el personal de los Cuerpos nacionales y subalternos, aumentando los restantes; sin embargo, en las plazas en propiedad, únicamente sufre aumentos el personal de servicios especiales.

El peso relativo del personal propietario en relación con el de plantilla decrece en todas las clases de funcionarios, excepto el incremento en relación con el personal subalterno. 


\section{LAS VACANTES Y EL PERSONAL JUBILADO}

La relación de plazas cubiertas en propiedad con el personal de plantilla permite deducir indirectamente las cifras absolutas y los valores relativos de las vacantes cubiertas con personal no propietario o sin cubrir, por clases de Corporaciones y funcionarios y nivales de población de los Municipios.

Las vacantes en las Corporaciones locales, en conjunto, cubiertas con personal no propietario y sin cubrir (del Anuario, cuadro 2.2) es en el ciclo 1969-1973 del 21,82 por 100 de aumento.

Las vacantes en las Diputaciones provinciales y Cabildos insulares cubiertas con personal no propietario y sin cubrir (del Anuario, cuadro 3.2) es en el ciclo citado del 20,46 por 100 de aumento.

$Y$ las vacantes en los Ayuntamientos de Municipios capitales de Provincia, con personal de iguales características (del Anuario, cuadro 6.2), es en el ciclo citado del 22,21 por 100 de aumento; con dicha tendencia en el personal de Cuerpos nacionales, administrativos, técnicos y servicios especiales, disminuyendo únicamente el personal subalterno.

$\mathrm{El}$ incremento de vacantes es general en este ciclo en todos los Ayuntamientos (cuadros 5.2-5.2.a, b, c, d, e) (3), disminuyendo el personal administrativo y subalterno en los Ayuntamientos de $\mathrm{Mu}$ nicipios menores de 1.001 habitantes, y únicamente los subalternos en el nivel de 20.001 a 100.000 habitantes; teniendo los demás una tendencia al aumento, excepto el personal de Cuerpos nacionales, que se estabiliza, y una ligera disminución el personal técnico del nivel de 1.001 a 5.000 habitantes.

En el año 1972 se jubilaron 293 funcionarios en las Diputaciones provinciales y Cabildos insulares (cuadro 14), 1.648 en los Ayuntamientos (cuadro 15) y en los Ayuntamientos de Municipios capitales de Provincia (cuadro 16) fueron 778, siendo los porcentajes respecto del personal que ocupa plaza en propiedad en las Diputaciones y Cabildos de 1,85 por 100, y en los Ayuntamientos, de 0,87 por 100 .

(3) Ver Anuario Estadistico de las Corporaciones Locales, Madrid, 1974. 


\section{CONCLUSIONES}

Podemos sintetizar en varias conclusiones generales el valor y significado de las cifras comentadas en los apartados anteriores. Se repiten las del Anuario Estadistico de las Corporaciones Locales, 1974, con algunos retoques, y se añaden otras.

Primera. Se aprecia en el quinquenio un aumento moderado del personal al servicio de las Corporaciones locales, más acusado en las Diputaciones y Cabildos y menor en los Ayuntamientos. De cada 100 personas en 1973 al servicio de las Corporaciones locales 21 prestan servicio en las Diputaciones y Cabildos insulares y 79 prestan servicio en los Ayuntamientos. Véase cuadro I.A.1.1.

Segunda. El incremento apuntado en la conclusión primera es débil con respecto al personal de plantilla y afecta de manera fundamental al personal sujeto a legislación laboral y al de servicios concertados.

El aumento del personal de plantilla, dentro de su limitación, se acentúa más en los Ayuntamientos y ofrece un nivel más bajo en las Diputaciones y Cabildos.

El personal laboral registra un fuerte incremento, casi de una quinta parte para el conjunto de Corporaciones, y en las Diputaciones y Cabildos el incremento casi es de la mitad, y en los Ayuntamientos el aumento es sólo de la décima parte.

El personal de servicios concertados registra un aumento menos acentuado y casi reducido a la mitad para las Corporaciones e igual para los Ayuntamientos, y respecto a las Diputaciones ofrece una disminución superior a la quinta parte.

Para el quinquenio 1969-1973 se observan más claramente dichas variaciones con el cuadro B.1.1.1.

El peso relativo del personal de plantilla tiende, una vez más, a decrecer en beneficio de los otros dos grupos. El aumento del personal laboral es más propio de las Diputaciones y Cabildos, mientras que el del personal de servicios concertados es más característico de los Ayuntamientos.

Atendiendo al número de personas que servían a las Corporaciones locales en 1973, de cada 100 personas 64 eran de plantilla, 29 de personal laboral y 7 de servicios concertados.

En 1973, en las Diputaciones y Cabildos, de cada 100 personas sólo 14 tienen la calificación de personal de plantilla, 52 personal su- 
jeto a legislación laboral y 4 personal de servicios concertados. $\mathrm{Y}$ en los Ayuntamientos, de cada 100 personas 69 son de plantilla, 22 son laborales y 9 de servicios concertados, valores análogos a los de 1972.

Para una comprensión más rápida de las variaciones presentamos el cuadro I.B.1.2.2.

Tercera. El incremento del personal no se produce con carácter general, puesto que el aumento se manifiesta en el personal de los Ayuntamientos de los grandes y de los pequeños Municipios, y en los restantes es cada vez más estacionaria. En el quinquenio, la distribución del personal al servicio de los Ayuntamientos se estudia en el cuadro I.C.1.1.1. Se acentúa la tendencia a la concentración del personal en los Ayuntamientos de los grandes Municipios, a los que sirven 44 personas de cada 100 funcionarios. Se puede afirmar que los Municipios mayores de 20.000 habitantes absorben el 65 por 100 del personal de todos los Ayuntamientos.

El personal de plantilla únicamente aumenta en los Ayuntamientos los niveles extremos de población, y decrece en los intermedios.

El personal laboral sigue en aumento en los Municipios mayores de 5.000 habitantes, y el personal de los servicios concertados aumenta en los Ayuntamientos de los grandes Municipios.

El personal de plantilla tiene un aumento relativo en los niveles de 1.001 a 5.000 y en los de más de 100.000 habitantes, y una disminución relativa en los niveles restantes. En el personal laboral no hay coincidencia o paralelismo con esos aumentos. $\mathrm{El}$ incremento del personal de servicios concertados es general y para todos los niveles, pero en especial el aumento es mayor en los grandes Municipios.

En la distribución interna del personal de los Ayuntamientos de cada 100, personas, en el nivel menor, 55 son de plantilla, 11 laborales y 34 de servicios concertados; en el segundo, de cada 100 personas 70 son de plantilla, 14 de laborales y 16 de servicios concertados; en el tercero, de cada 100 corresponden 65 al personal de plantilla, 25 al personal laboral y 10 al de servicios concertados; en el cuarto, de cada 100 personas, 63 comprenden al personal de plantilla, 33 al personal laboral y 4 al de servicios concertados, y en el quinto nivel, de cada 100 personas, 76 son de plantilla, 20 de personal laboral y 4 de servicios concertados. 
Más de las dos terceras partes pertenecen a Ayuntamientos de Municipios mayores de 20.000 habitantes.

Cuarta. Los Ayuntamientos de los Municipios capitales de Provincia registran un incremento de personal del 6 por 100. El personal de plantilla ha aumentado más del doble respecto del ciclo anterior; el personal sujeto a legislación laboral ha disminuido y el personal de servicios concertados ha aumentado en el quinquenio, según se puede observar en el cuadro I.1.D.1.1.

Quinta. Teniendo en cuenta el análisis del personal de plantilla, se aprecia una disminución que no llega al 4 por 100 en el personal de los Cuerpos nacionales, se acentúa en el Cuerpo subalterno al acercarse al 9 por 100 , un aumento del 5 por 100 en el personal administrativo, un suave aumento en el personal técnico y un incremento pronunciado, de casi un 7 por 100 , en el personal de servicios especiales.

En los Ayuntamientos discurre la variación como en las Corporaciones en general, excepto en el personal técnico, que permanece estable. En. las Diputaciones y Ayuntamientos es análogo el aumento del personal administrativo.

En las Diputaciones y Cabildos es muy reducido el peso relativo del personal de Cuerpos nacionales, los administrativos y técnicos destacan sobre los de los Ayuntamientos en un 3 por 100, y el personal subalterno disminuye con más intensidad en los Ayuntamientos.

Todo ello se puede observar rápidamente, para el quinquenio, en el cuadro I.1.E.1.1.

En los Cuerpos nacionales se registra una disminución que no llega al 4 por 100, y se acentúa en los subalternos, con el 9 por 100 , y un suave aumento el personal técnico y un incremento pronunciado el personal de servicios especiales.

En los Ayuntamientos, el personal técnico permanece estable y los subalternos disminuyen respecto a lo que ocurre en las Diputaciones y Cabildos, mientras que en las Diputaciones y Cabildos y Ayuntamientos es análogo el aumento de personal administrativo y el de servicios especiales, con ligero aumento dentro del mismo de los Ayuntamientos respecto de las Diputaciones y Cabildos.

En los Cuerpos nacionales, en conjunto, ha permanecido estable respecto de 1972, pero ha tenido una tendencia a la baja desde 1969, apreciándose una disminución de efectivos en los Cuerpos de Depositarios y Directores de Bandas de Música. 
En el personal administrativo, en conjunto, se observa un incremento anual aproximado de 200 personas, disminuyendo los oficiales mayores en las Corporaciones.

En el personal técnico de las Corporaciones, en conjunto, se aprecia una disminución de unos 50 por año, sobre todo en la escala inferior.

En el personal de servicio especiales de las Corporaciones, en conjunto, hay un aumento progresivo anual de unas 800 personas, sobre todo en guardias y bomberos.

En el personal de Cuerpos nacionales, en conjunto, hay un trueque con respecto a lo ocurrido en el ciclo anterior, porque en el nivel de hasta 1.000 habitantes hay un crecimiento; en el de 1.001 a 5.000, una baja profunda; en el 5.001 a 20.000 , una baja pronunciada; en el nivel de 20.001 a 100.000 , una subida suave, y en los Municipios mayores, un aumento progresivo de cinco por año.

En el personal administrativo crece el de los Municipios de menos de 1.001 habitantes, y en los demás niveles decrecen o permanecen estables. En el personal técnico, en conjunto, únicamente permanece estable el nivel superior a 100.000 habitantes; las matronas tienden a desaparecer en varios niveles y en el nivel superior disminuyen levemente.

El personal de servicios especiales aumenta, y el subalterno aumenta en el nivel superior a 100.000 habitantes y disminuye en los demás.

Sexta. El personal que cubre plaza en propiedad y su relación con el personal de plantilla viene señalado para el quinquenio 19691973 en el cuadro I.2.A.1.1, y está en la relación de cuatro a cinco.

Si estudiamos la evolución del personal que cubre plaza en propiedad y personal de plantilla en relación con los niveles de población de los Municipios, lo veremos rápidamente en el cuadro I.2.B.1.1, resultando fácil el comentario.

Y si queremos ver la evolución del personal propietario en relación con el de plantilla en los Ayuntamientos de los Municipios capitales de Provincia, no tenemos más que observar la tabla I.2.B.3.1 del Anuario Estadístico de las Corporaciones Locales, 1974.

Séptima. Voy a señalar: 1. El indice de burocratización que existe en las Corporaciones locales en el ciclo señalado, comparando el número de administrativos con el total de funcionarios, en el personal de plantilla y que cubre plaza en propiedad; $2 .^{\circ}$ El indice 
de profesionalidad, como cociente entre técnicos titulados y el total de funcionarios, y 3.० El indice de cualificación laboral, como cociente de obreros cualificados y el total de funcionarios, dando el

\section{CUADRO I.2.A.3}

\begin{tabular}{|c|c|c|}
\hline \multirow[b]{3}{*}{$\begin{array}{lllllllll}\text { Indice de burocratización } & \ldots & \ldots & \ldots & \ldots & \ldots & \ldots & \ldots & \ldots \\
\text { Indice de profesionalidad } & \ldots & \ldots & \ldots & \ldots & \ldots & \ldots & \ldots & \ldots \\
\text { Indice de cualificación laboral } & \ldots & \ldots & \ldots & \ldots & \ldots & \ldots\end{array}$} & \multicolumn{2}{|c|}{1969} \\
\hline & $\begin{array}{l}\text { Diputaciones } \\
\text { y Cabildos }\end{array}$ & Ayuntamientos \\
\hline & $\begin{array}{l}0,23 \\
0,23 \\
0,43\end{array}$ & $\begin{array}{l}0,19 \\
0,06 \\
0,21\end{array}$ \\
\hline \multirow[b]{3}{*}{$\begin{array}{lllllllll}\text { Indice de burocratización } & \ldots & \ldots & \ldots & \ldots & \ldots & \ldots & \ldots & \ldots \\
\text { Indice de profesionalidad } & \ldots & \ldots & \ldots & \ldots & \ldots & \ldots & \ldots & \ldots \\
\text { Indice de cualificación laboral } & \ldots & \ldots & \ldots & \ldots & \ldots & \ldots\end{array}$} & \multicolumn{2}{|c|}{1970} \\
\hline & $\begin{array}{l}\text { Diputaciones } \\
\text { y Cabildos }\end{array}$ & Ayuntamientos \\
\hline & $\begin{array}{l}0,25 \\
0,20 \\
0,46\end{array}$ & $\begin{array}{l}0,19 \\
0,06 \\
0,22\end{array}$ \\
\hline \multirow[b]{3}{*}{$\begin{array}{lllllllll}\text { Indice de burocratización } & \ldots & \ldots & \ldots & \ldots & \ldots & \ldots & \ldots & \ldots \\
\text { Indice de profesionalidad } & \ldots & \ldots & \ldots & \ldots & \ldots & \ldots & \ldots & \ldots \\
\text { Indice de cualificación laboral } & \ldots & \ldots & \ldots & \ldots & \ldots & \ldots\end{array}$} & \multicolumn{2}{|c|}{1971} \\
\hline & $\begin{array}{l}\text { Diputaciones } \\
\text { y Cabildos }\end{array}$ & Ayuntamientos \\
\hline & $\begin{array}{l}0,23 \\
0,23 \\
0,47\end{array}$ & $\begin{array}{l}0,18 \\
0,06 \\
0,21\end{array}$ \\
\hline & \multicolumn{2}{|c|}{1972} \\
\hline & $\begin{array}{c}\text { Diputaciones } \\
\text { y Cabildos }\end{array}$ & Ayuntamientos \\
\hline $\begin{array}{lllllllll}\text { Indice de burocratización } & \ldots & \ldots & \ldots & \ldots & \ldots & \ldots & \ldots & \ldots \\
\text { Indice de profesionalidad } & \ldots & \ldots & \ldots & \ldots & \ldots & \ldots & \ldots & \ldots \\
\text { Indice de cualificación laboral } & \ldots & \ldots & \ldots & \ldots & \ldots & \ldots\end{array}$ & $\begin{array}{l}0,23 \\
0,24 \\
0,48\end{array}$ & $\begin{array}{l}0,18 \\
0,06 \\
0,22\end{array}$ \\
\hline & \multicolumn{2}{|c|}{1973} \\
\hline . & $\begin{array}{l}\text { Diputaciones } \\
\text { y Cabildos }\end{array}$ & Ayuntamientos \\
\hline $\begin{array}{lllllllll}\text { Indice de burocratización } & \ldots & \ldots & \ldots & \ldots & \ldots & \ldots & \ldots & \ldots \\
\text { Indice de profesionalidad } & \ldots & \ldots & \ldots & \ldots & \ldots & \ldots & \ldots & \ldots \\
\text { Indice de cualificación laboral } & \ldots & \ldots & \ldots & \ldots & \ldots & \ldots\end{array}$ & $\begin{array}{l}0,24 \\
0,24 \\
0,52\end{array}$ & $\begin{array}{l}0,19 \\
0,06 \\
0,22\end{array}$ \\
\hline
\end{tabular}

Se observa en los dos primeros índices y en Diputaciones y Cabildos insulares una gran estabilidad, pero no así en el índice de cualificación laboral, que ha tenido en el quinquenio un aumento del 9 por 100 .

En los Ayuntamientos la estabilidad es muy pronunciada. 
Octava. Voy a calcular el coeficiente de autocorrelación de la serie temporal del personal al servicio de las Corporaciones en conjunto, tomando un desfase de un año, y he Ilegado a la conclusión, confirmando lo dicho anteriormente, de que si hay dependencia entre los valores de un año y los del anterior en el período 19691973, siendo casi perfecta la correlación, ya que con el

\section{CUADRO I.2.A.4}

PERSONAL AL SERVICIO DE LAS CORPORACIONES EN CONJUNTO

\begin{tabular}{|c|c|c|c|c|c|c|c|c|}
\hline \multicolumn{4}{|c|}{ Años } & $Y_{t}$ & $Y_{t-1}$ & $Y_{t} \cdot Y_{t-1}$ & $Y_{t}^{2}$ & $Y_{t-1}^{2}$ \\
\hline \multirow{7}{*}{$\begin{array}{l}1968 \\
1969 \\
1970 \\
1971 \\
1972 \\
1973\end{array}$} & $\ldots$ & $\ldots$ & & (182.244) & - & - & - & - \\
\hline & $\ldots$ & $\ldots$ & $\ldots$ & 187.167 & 182.244 & 34.110 .062 .748 & 35.031 .485 .889 & 33.212 .875 .536 \\
\hline & & $\cdots$ & $\ldots$ & 189.655 & 187.167 & 35.497 .157 .385 & 35.969 .019 .025 & 35.031 .485 .889 \\
\hline & & $\ldots$ & $\ldots$ & 193.329 & 189.655 & 36.665 .811 .495 & 37.376 .102 .241 & 35.969 .019 .025 \\
\hline & $\ldots$ & $\ldots$ & $\ldots$ & 197.572 & 193.329 & 38.196.397.188 & 39.034.695.184 & 37.376 .102 .241 \\
\hline & $\ldots$ & $\cdots$ & ... & 204.324 & 197.572 & 40.368 .701 .328 & 41.748 .296 .976 & 39.034 .695 .184 \\
\hline & & & & 972.047 & 949.572 & 184.838 .130 .144 & 189.159.599.315 & 180.624 .177 .875 \\
\hline
\end{tabular}

y teniendo en cuenta el coeficiente de correlación, siendo el numerador la covarianza y el denominador el producto de las desviaciones típicas de las dos series, se deduce

$$
\begin{aligned}
& Y_{t, t-1}=\frac{S_{t}, t-1}{S_{t} \cdot S_{t-1}}= \\
& \frac{1}{N} \Sigma Y_{t} \cdot Y_{t-1}-\frac{1}{N} \Sigma Y_{t} \cdot \frac{1}{N} \Sigma Y_{t-1} \\
& =\frac{\sqrt{\frac{\Sigma Y_{t}^{2}}{N}-\left(\frac{\Sigma Y_{t}}{N}\right)^{2}} \cdot \sqrt{\frac{\Sigma Y_{t-1}^{2}}{N}-\left(\frac{\Sigma Y_{t-1}}{N}\right)^{2}}}{N}= \\
& \frac{1}{5} \cdot(184.838 .130 .144)-\frac{1}{5} \cdot(972.047) \cdot \frac{1}{5} \cdot(949.067) \\
& =\frac{5}{\sqrt{\frac{189.159 .599 .315}{5}-\left(\frac{972.047}{5}\right)^{2}} \cdot \sqrt{\frac{180.624 .177 .875}{5}-\left(\frac{949.967}{5}\right)^{2}}}= \\
& =0,98
\end{aligned}
$$

valor tan próximo a 1 que nos señala la casi perfecta correlación. 
REVL-1975, núm. 187. RODRIGUEZ SOCORRO, ANTONIO. ESTUDIO ESTADISTICO DE LOS FUNC...

REVISTA

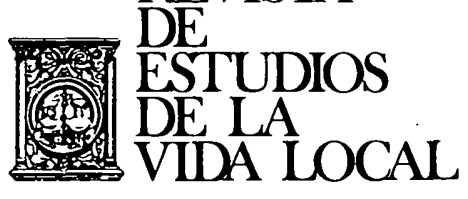

IV. JURISPRUDENCIA

REVL-1975, núm. 187. RODRIGUEZ SOCORRO, ANTONIO. ESTUDIO ESTADISTICO DE LOS FUNC... 
REVL-1975, núm. 187. RODRIGUEZ SOCORRO, ANTONIO. ESTUDIO ESTADISTICO DE LOS FUNC... 